\title{
Daily Monsoon Rainfall Prediction using Artificial Neural Network (ANN) for Parbhani District of Maharashtra, India
}

\author{
Amit Rawat ${ }^{1}$, Pravendra Kumar ${ }^{2}$ and Vaibhav Deoli ${ }^{3 *}$ \\ ${ }^{1}$ Department of Civil Engineering, Institute of Technology, Gopeshwar-246424, India \\ ${ }^{2}$ Department of Soil and Water Conservation Engineering, \\ GBPUA\&T Pantnagar-263145, India \\ ${ }^{3}$ Department of Civil Engineering, Inderprastha Engineering College, \\ Sahibabad, Ghaziabad-201010, India \\ *Corresponding author
}

\section{A B S T R A C T}

Keywords

Maharashtra, India,

Monsoon season,

Human culture,

Hydrology

Article Info

Accepted:

15 November 2019

Available Online:

10 December 2019
Rainfall is the most complex and difficult elements of hydrological cycle to understand and to model due to the complexity of atmospheric process. Long term prediction of rainfall is important for country like India where economy is mainly depends on agriculture. In the present study an attempt has been made to develop ANN models for prediction of daily rainfall for monsoon season at Parbhani District of Maharashtra, India. For the study, 30 years data (1985 to 2014) have been used. The $80 \%$ data (1985-2008) were used for model calibration and remaining 20\% data (2008-2014) were used for validation. In the study, Gama test has been used to find best combination of input variables and after that back-propagation algorithm and tan sigmoid activation function were used to train and test the models. It was founded that the models are capable to predict the rainfall with adequate accuracy.

\section{Introduction}

The critical dependence of human culture on a reliable source of water and its requirement for security from floods and dry seasons resulted in the branch of science, hydrology, which has principally developed in the journey for solutions to water related issues. During rainy season between June to September, south-west monsoon contributes more than $75 \%$ of the annual rainfall of India (Singh, 2006). The view of Indian agriculture is very much dependent on beginning of monsoon and depth of rainfall during rainy season. 
Therefore, any decrease or increase in annual rainfall will always have severe impact on the agriculture sector of India. Therefore, it is essential to forecast the monsoon behaviour which will help the farmers and the government to take full advantage of monsoon season. This knowledge can be vital in reducing the damage of crops during low rainfall periods in monsoon seasons. Rainfall is natural climatic phenomena whose prediction is very challenging and demanding. Accurate study on rainfall is vital for the planning and management of the water resources. Nevertheless, rainfall is one of the most complex and difficult element of the hydrological cycle to understand and to model due to the complexity of the atmospheric processes that generate rainfall and tremendous range of variation over a wide range of scales both in space and time (French et al., 1992).

For achieving predictions there are a number of methods, ranging from naive methods to those that use more complex techniques such as artificial intelligence (AI), artificial neural networks (ANNs) being one of the most valuable and attractive methods for forecasting tasks. In prediction, ANNs, as opposed to traditional methods in meteorology, are based on self-adaptive mechanisms that learn from examples and capture functional relationships between data, even if the relationships are unknown or difficult to describe.

Artificial neural network (ANNs) has been proven to be very useful in dealing with highly complicated problems due to their capability to model nonlinear systems without the need to make any assumptions. A review of ANNs in hydrology was presented by ASCE task committee on application of ANNs in hydrology (ASCE, 2000a and ASCE, 2000b). ANN have found increasing application for modelling hydrological processes (Jain and
Srivastava, 1999; Tokar and Markus, 2000; Luk et al., 2001; Jyothiprakash et al., 2002; Agrawal et al., 2006; Rajukar et al., 2004; Kumar and Jain, 2007; Gadgey et al., 2011; El-shafie et al., 2011a, b). Additional some studies were performed to examine the potential of combining ANNs with other computing algorithms (Lin and Chen, 2005; $\mathrm{Wu}$ and chau, 2006 and Xie et al., 2006). Various applications of ANNs for hydrological forecasting (Lin and Chen, 2004; Ramirez et al., 2005; Pulido-Calvo and Portela, 2007 and Partal and Cigizoglu, 2008) were studied in recent years. Gadgay et al., (2011) developed artificial neural network (ANN) models to predict the rainfall for Bangalore city of India using Single neural network (SNN) and Ensemble neural network (ENN) models. The ANN models were trained and tested with the corresponding rainfall data which was collected in the last three years on hourly basis. Authors concluded the results predicted by the SNN and ENN models are compared with the actual data and error as well as percentage errors was computed. Nastos et al., (2013) developed predictive models in order to forecast rain intensity $(\mathrm{mm} /$ day) in Athens, Greece using artificial neural network (ANN) models. The ANNs outcomes concern the projected mean, maximum and minimum monthly rain intensity for the next four consecutive months in Athens. The metrological data used to estimate the rain intensity were the monthly rain totals $(\mathrm{mm})$. The results of the developed and applied ANN models showed fairly reliable forecast of rain intensity for the next four months. Pai et al., (2014) forecasted southwest Indian monsoon rainfall making use of ANN with sea level pressure, sea surface temperature, humidity and zonally and meridional winds. Input parameters data of 36 years and 9 years were used for training and testing of the models respectively. The results of validation period of June, July, August and September showed very closeness with 
observed values. Mishra et al., (2018) analysed that with the help of time series data method, accurate rainfall can be predicted and it will help in effective evaluation of drought and floods. They used ANN technique for rainfall prediction using time series data for one-month and two-month ahead rainfall forecasting model using monthly time series rainfall data of North India for the period 1871 to 2012 (i.e. 141 years).

Keeping the above reviews in mind, this study was conducted with the following specific objectives: (i) To select the best combination of input parameter using Gamma Test (ii) To develop ANN model with multi-resolution analysis to predict daily rainfall for monsoon period (iii) To validate developed models for the study area and (iv) To assess the performance of developed models for the study area through qualitative comparisons and to identify the best suited model.

\section{Materials and Methods}

\section{Study area}

Parbhani district was known as "Prabhavati" in ancient times. It is located towards east of Maharashtra and it is one of the eight districts of Marathwada division. The latitude and longitudes of study area is $18.27^{\circ}$ to $20.01^{\circ} \mathrm{N}$ and $76.13^{\circ}$ to $77^{\circ} \mathrm{E}$. The elevation of the area is $347 \mathrm{~m}$ above mean sea level. The location of study area is shown in Figure 1. The climate of study area is classified as the tropical. In general the climate of the area is dry during the southwest monsoon season. The year can be divided into four seasons. The cold season from December to February and the hot season (March to May), the southwest monsoon season from June to September and the post-monsoon season from October to November. The annual average rainfall in the area is $888.5 \mathrm{~mm}$. The daily meteorological data of 30 years (1985-2014) were collected from the meteorological observatory of Vasantrao Naik Marathwada Krishi Vidyapeeth, Parbhani, Maharastra State, India.

\section{Pre-analysis and formulation of data}

The data required for this study were collected of the period ( $1^{\text {st }}$ June to $30^{\text {th }}$ September) for thirty years from 1985 to 2014 .

These data involved daily values of rainfall, temperature, relative humidity and wind velocity and were subjected to pre-analysis and formulation of data base. The $80 \%$ data (1985-2008) were used for model calibration and remaining $20 \%$ data (2008-2014) were used for validation.

\section{Artificial Neural Network (ANN)}

A typical neuron of the ANN consists of input: to Propagates input signal to neuron, Synaptic weights: Interneuron connections that weighs their respective input signals, Bias: Threshold that has an effect of either increasing or decreasing the net input and Output: to provides the output signal of the neuron. The basic structure of a neural network is shown in Figure 2.

In neural network, every neuron has a number of inputs and outputs. A neuron calculates an output by applying net and transfer function on inputs.

First, net function sum weighted inputs (u) and then output is calculated based on transfer function. The net function is usually linear, as follows;

$$
u=\sum_{i=1}^{N} \quad x_{i} W_{i}+b \ldots \text { (1) }
$$

where $x_{i}$, is an input vector, $W_{i}$ is the connection weight from the $i^{\text {th }}$ neuron in the input layer and $b$ is the threshold value or the bias of the neuron. 
Development of ANN models for rainfall prediction

In present study, the neural networks and wavelet transformed ANN models have been applied to predict the monsoon rainfall on daily basis for Parbhani area in Maharastra, India. It has been reported by Hung et al., (2008) that the combination of meteorological parameter (relative humidity, vapour pressure, temperature and rainfall) as an input for training of the model was found the most satisfactory for forecasting.

Therefore, in this study, observed daily time series of temperature, relative humidity, wind speed, vapour pressure and rainfall of the monsoon season during the years were considered for development of models. Because of rainfall process is dynamic in nature and it requires proper time lag for its modelling.

For this purpose current day rainfall is considered to be a function of current day temperature, relative humidity, wind velocity, vapour pressure and rainfall. Let the value of temperature, relative humidity, wind velocity, rainfall and vapour pressure represented as $T_{\mathrm{ij}}$, $\mathrm{RH}_{\mathrm{ij}}, \mathrm{V}_{\mathrm{ij}}, \mathrm{P}_{\mathrm{ij}}$ and $\mathrm{VP}_{\mathrm{ij}}$ respectively, then the functional form of rainfall modeling can be expressed as,

$\mathrm{P}_{\mathrm{ij}}=f\left(\mathrm{~T}_{\mathrm{ij}}, \mathrm{Tij}_{-1} \ldots \mathrm{T}_{\mathrm{ij}-\mathrm{m}}, \mathrm{RH}_{\mathrm{ij}}, \mathrm{RH}_{\mathrm{ij}-1} \ldots \mathrm{RH}_{\mathrm{ij}-\mathrm{m}}\right.$, Vij, $\left.V_{i j}-1 \ldots V_{i j-m}, P_{i j-1} \ldots P_{i j-m}, B_{i j}\right) \ldots$ (2) in which, $m$ denotes the lag time which is taken as two in this study. The formulated year wise meteorological data is shown in Table 1.

\section{Gamma test}

Finding out and selecting the most important and effective variables of a nonlinear and unknown function the Gamma test (GT) was used in this study. A main advantage of this tool is its speed in large databases which consisting thousands points for data sets, While a single run of the GT takes a few seconds. In a set of input-output data, The GT estimates the minimum mean square error (MSE) that achieve by a smooth model, this estimate is called GT statistic. Suppose we have a set of data observations, $\left\{\left(\mathrm{x}_{\mathrm{i}}, \mathrm{y}_{\mathrm{i}}\right), 1 \leq \mathrm{i}\right.$ $\leq \mathrm{M}$ \} that the output $\mathrm{y}$ is determined by $x$ input vectors, where xi $\in R_{m}$ are vectors confined to some closed bounded set $\mathrm{C} \in \mathrm{R}_{\mathrm{m}}$; and $\mathrm{y}_{\mathrm{i}} \in \mathrm{R}$ is associated output scalar. In this method, relationship between input-output can be written as:

$y=f(x)+r \ldots(3)$

where, $\mathrm{f}$ and $\mathrm{r}$ are a smooth function and a random variable, respectively. $\mathrm{r}$ represents noise (part of output which cannot be calculated by any smooth model).

The GT is an estimate of the model output variance that cannot be calculated by a smooth data model. The GT is based on the $\mathrm{k}^{\text {th }}(1 \leq \mathrm{k}$ $\leq$ p) nearest neighbours $x_{\mathrm{N}[i, \mathrm{k}]}$ for each vector $\mathrm{x}_{\mathrm{i}}(1 \leq \mathrm{i} \leq \mathrm{M})$. Specifically, the GT is derived from the delta function of the input vectors:

$\delta_{\mathrm{M}}(\mathrm{k})=\frac{1}{M} \sum_{i=1}^{M} \quad|x i-x N[i, k]|^{2}$

$1 \leq \mathrm{k} \leq \mathrm{p}$

where, $|\ldots|$ denotes Euclidean distance, and Gamma function is given as following

$\gamma_{\mathrm{M}}(\mathrm{k})=\frac{1}{2 M} \sum_{i=1}^{M} \quad|y i-y N i, k|^{2}$

$1 \leq \mathrm{k} \leq \mathrm{p}$

where, $\mathrm{y}_{\mathrm{N}[\mathrm{i}, \mathrm{k}]}$ is the corresponding $\mathrm{y}$-value for the $\mathrm{k}^{\text {th }}$ nearest neighbour of $x_{i}$ in Eq. (5). The GT is computed based on a Least Squares regression line which is constructed for $\mathrm{p}$ points $\left[\delta_{\mathrm{M}}(\mathrm{k}), \gamma_{\mathrm{M}}(\mathrm{k})\right]$ :

$\gamma=\mathrm{A} \delta+\mathrm{GT} \ldots(6)$ 
The intercept on the vertical axis $(\delta=0)$ is the GT value, it can be shown that $\gamma_{M}(\mathrm{k}) \rightarrow \operatorname{Var}(\mathrm{r})$ in probability is as $\gamma_{M}(\mathrm{k}) \rightarrow 0$. The gradient of regression line provides the useful information on complexity of the system under study. The GT offers an estimate of the best MSE achievable using a modelling technique for unknown smooth functions of continuous variables. The GT is a mathematical algorithm, which reduces volume of model development work and creates guidance for proper needed input data and the most important variables before developing model.

\section{Development of ANN model}

In this method, the observed time series of temperature, relative humidity, wind speed and vapour pressure data were used as an inputs as per the best combination given by the Gamma test, model 8 gave the lowest value of gamma hence it is used for modelling inputs for rainfall prediction. Consider the monsoon season starting from $1^{\text {st }}$ June to September $30^{\text {th }}$ only. In this case $\mathrm{N}=122$ days $\left(1^{\text {st }}\right.$ June to $30^{\text {th }}$ September) in a year and $\mathrm{M}=$ 30 years (1984-2014).

The functional form of the model can be represented as

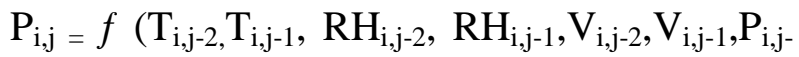

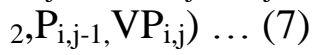

This functional form can be represented diagrammatically in Figure 3.

\section{Results and Discussion}

\section{Gamma test}

The best-input combination for application to a model was identified using the Gamma Test (GT). The results of gamma test are shown in Table 3. The best combination of input variables was selected based on the least value of Gamma statistic. Therefore, out of 10 models tested for input combinations, it is found that the model that gives the minimum value of gamma is model 8 and thus, it was selected for input-combination for further application in predictions of rainfall using various models.

\section{Artificial neural network model}

The artificial neural network (ANN) models were trained using multilayer feed-forward neural network with varying number of neurons in single and double hidden layers using hyperbolic tangent activation function. The analysis of different structures of ANN models trained and tested for maximum epoch's value of 1000 and threshold's value as 0.001 . The daily monsoon rainfall prediction model for a study area has been developed using the combination of the best input parameters given by Gamma test as discussed under Figure 4 i.e. current day vapour pressure and one day and two lag day rainfall, relative humidity, wind speed and temperature, respectively.

\section{Development of rainfall prediction model}

Rainfall prediction models were developed for study area using Artificial Neural Networks (ANN) approach. The value of performance evaluation indices using selected ANN models for the estimation of daily monsoon rainfall is depicted in Table 4. A few of networks with single and double hidden layers having very low value of RMSE and the highest value of $r$ and CE. The values of correlation coefficient (r) for various ANN network architectures varying from 0.65 to 0.91 . The values for RMSE ranges from 7.26 to 13.33 and $\mathrm{CE}$ values lie between 0.42 and 0.86 . It is clear from Table that the performance of the models ANN (9-11-1) and (9-8-8-1) is better than other single and double hidden layers models, respectively. 
Table.1 Year wise hydrological data

\begin{tabular}{|c|c|c|c|c|c|c|}
\hline Year & Days & $\begin{array}{c}\text { Temperature } \\
\text { (T) }\end{array}$ & $\begin{array}{c}\text { Relative } \\
\text { humidity } \\
\text { (RH) }\end{array}$ & $\begin{array}{l}\text { Wind } \\
\text { velocity } \\
\text { (V) }\end{array}$ & Vapour pressure (VP) & $\begin{array}{l}\text { Rainfall } \\
\text { (P) }\end{array}$ \\
\hline \multirow[t]{5}{*}{1} & 1 & $\mathrm{~T}_{11}$ & $\mathrm{RH}_{11}$ & $\mathrm{~V}_{11}$ & $\mathrm{VP}_{11}$ & $\mathrm{P}_{11}$ \\
\hline & 2 & $\mathrm{~T}_{12}$ & $\mathrm{RH}_{12}$ & $\mathrm{~V}_{12}$ & $\mathrm{VP}_{12}$ & $\mathrm{P}_{12}$ \\
\hline & 3 & $\mathrm{~T}_{13}$ & $\mathrm{RH}_{13}$ & $\mathrm{~V}_{13}$ & $\mathrm{VP}_{13}$ & $\mathrm{P}_{13}$ \\
\hline & $\ldots$ & $\ldots$ & $\ldots$ & $\ldots$ & $\ldots$ & $\ldots$ \\
\hline & $\mathrm{N}$ & $\mathrm{T}_{1 \mathrm{n}}$ & $\mathrm{RH}_{1 \mathrm{n}}$ & $V_{1 n}$ & $\mathrm{VP}_{1 \mathrm{n}}$ & $\mathrm{P}_{1 \mathrm{n}}$ \\
\hline \multirow[t]{5}{*}{2} & 1 & $\mathrm{~T}_{21}$ & $\mathrm{RH}_{21}$ & $\mathrm{~V}_{21}$ & $\mathrm{VP}_{21}$ & $\mathrm{P}_{21}$ \\
\hline & 2 & $\mathrm{~T}_{22}$ & $\mathrm{RH}_{22}$ & $\mathrm{~V}_{22}$ & $\mathrm{VP}_{22}$ & $\mathrm{P}_{22}$ \\
\hline & 3 & $\mathrm{~T}_{23}$ & $\mathrm{RH}_{23}$ & $\mathrm{~V}_{23}$ & $\mathrm{VP}_{23}$ & $\mathrm{P}_{23}$ \\
\hline & $\ldots$ & $\ldots$ & $\ldots$ & $\ldots$ & $\ldots$ & $\ldots$ \\
\hline & $\mathrm{N}$ & $\mathrm{T}_{2 \mathrm{n}}$ & $\mathrm{RH}_{2 \mathrm{n}}$ & $\mathrm{V}_{2 \mathrm{n}}$ & $\mathrm{VP}_{2 \mathrm{n}}$ & $\mathrm{P}_{2 \mathrm{n}}$ \\
\hline \multirow[t]{5}{*}{3} & 1 & $\mathrm{~T}_{31}$ & $\mathrm{RH}_{31}$ & $\mathrm{~V}_{31}$ & $\mathrm{VP}_{31}$ & $\mathrm{P}_{31}$ \\
\hline & 2 & $\mathrm{~T}_{32}$ & $\mathrm{RH}_{32}$ & $\mathrm{~V}_{32}$ & $\mathrm{VP}_{32}$ & $\mathrm{P}_{32}$ \\
\hline & 3 & $\mathrm{~T}_{33}$ & $\mathrm{RH}_{33}$ & $\mathrm{~V}_{33}$ & $\mathrm{VP}_{33}$ & $\mathrm{P}_{33}$ \\
\hline & $\cdots$ & $\cdots$ & $\cdots$ & $\ldots$ & $\ldots$ & $\ldots$ \\
\hline & $\mathrm{N}$ & $T_{3 n}$ & $\mathrm{RH}_{3 \mathrm{n}}$ & $V_{3 n}$ & $\mathrm{VP}_{3 \mathrm{n}}$ & $\mathrm{P}_{3 \mathrm{n}}$ \\
\hline$\cdots$ & $\cdots$ & $\cdots$ & $\cdots$ & $\cdots$ & $\cdots$ & $\cdots$ \\
\hline \multirow[t]{5}{*}{ I } & 1 & $\mathrm{~T}_{\mathrm{i} 1}$ & $\mathrm{RH}_{\mathrm{i} 1}$ & $V_{i 1}$ & $\mathrm{VP}_{\mathrm{i} 1}$ & $P_{i 1}$ \\
\hline & 2 & $\mathrm{~T}_{\mathrm{i} 2}$ & $\mathrm{RH}_{\mathrm{i} 2}$ & $V_{i 2}$ & $\mathrm{VP}_{\mathrm{i} 2}$ & $\mathrm{P}_{\mathrm{i} 2}$ \\
\hline & 3 & $\mathrm{~T}_{\mathrm{i} 3}$ & $\mathrm{RH}_{\mathrm{i} 3}$ & $V_{i 3}$ & $\mathrm{VP}_{\mathrm{i} 3}$ & $\mathrm{P}_{\mathrm{i} 3}$ \\
\hline & $\cdots$ & $\ldots$ & $\ldots$ & $\ldots$ & $\ldots$ & $\ldots$ \\
\hline & $\mathrm{N}$ & $\mathrm{T}_{\mathrm{in}}$ & $\mathrm{RH}_{\text {in }}$ & $V_{\text {in }}$ & $V P_{\text {in }}$ & $P_{\text {in }}$ \\
\hline$\ldots$ & $\ldots$ & $\ldots$ & $\ldots$ & $\ldots$ & $\ldots$ & $\ldots$ \\
\hline \multirow[t]{4}{*}{$\mathbf{M}$} & 1 & $\mathrm{~T}_{\mathrm{M} 1}$ & $\mathrm{RH}_{\mathrm{M} 1}$ & $\mathrm{~V}_{\mathrm{M} 1}$ & $\mathrm{VP}_{\mathrm{M} 1}$ & $\mathrm{P}_{\mathrm{M} 1}$ \\
\hline & 2 & $\mathrm{~T}_{\mathrm{M} 2}$ & $\mathrm{RH}_{\mathrm{M} 2}$ & $\mathrm{~V}_{\mathrm{M} 2}$ & $\mathrm{VP}_{\mathrm{M} 2}$ & $\mathrm{P}_{\mathrm{M} 2}$ \\
\hline & 3 & $\mathrm{~T}_{\mathrm{M} 3}$ & $\mathrm{RH}_{\mathrm{M} 3}$ & $\mathrm{~V}_{\mathrm{M} 3}$ & $\mathrm{VP}_{\mathrm{M} 3}$ & $\mathrm{P}_{\mathrm{M} 3}$ \\
\hline & $\mathrm{N}$ & $\mathrm{T}_{\mathrm{Mn}}$ & $\mathrm{RH}_{\mathrm{Mn}}$ & $V_{M n}$ & $\mathrm{VP}_{\mathrm{Mn}}$ & $\mathrm{P}_{\mathrm{Mn}}$ \\
\hline
\end{tabular}


Table. 2 Selection of the best-input parameters based on the Gamma test

\begin{tabular}{|c|c|c|c|c|c|c|}
\hline \multirow{2}{*}{$\begin{array}{c}\text { Model. } \\
\text { No. }\end{array}$} & \multirow[t]{2}{*}{ Input } & \multirow[t]{2}{*}{ Mask } & \multicolumn{4}{|c|}{ Results of Gamma test } \\
\hline & & & Gamma & Gradient & S. Error & $\mathbf{V}_{\text {ratio }}$ \\
\hline 1 & $\begin{array}{c}\mathrm{T}_{\mathrm{ij}}, \mathrm{T}_{\mathrm{ij}-1}, \mathrm{~T}_{\mathrm{ij}-2,}, \mathrm{RH}_{\mathrm{ij}} \\
\mathrm{RH}_{\mathrm{ij}-1} \mathrm{RH}_{\mathrm{ij}-2} \\
\mathrm{~V}_{\mathrm{ij}}, \mathrm{V}_{\mathrm{ij}-1}, \mathrm{~V}_{\mathrm{i}, \mathrm{j}-1}, \mathrm{P}_{\mathrm{ij}-} \\
{ }_{1}, \mathrm{P}_{\mathrm{ij}-2}, \mathrm{VP}_{\mathrm{ij}}\end{array}$ & 111111111111 & 0.1520 & 0.0548 & 0.0548 & 0.6083 \\
\hline 2 & $\begin{array}{c}\mathrm{T}_{\mathrm{ij}-1,1} \mathrm{~T}_{\mathrm{ij}-2,2} \mathrm{RH}_{\mathrm{ij}} \\
\mathrm{RH}_{\mathrm{ij}-1} \mathrm{RH}_{\mathrm{ij}-2} \\
\mathrm{~V}_{\mathrm{ij}}, \mathrm{V}_{\mathrm{ij}-1}, \mathrm{~V}_{\mathrm{i}, \mathrm{j}-1}, \mathrm{P}_{\mathrm{ij}-} \\
{ }_{1}, \mathrm{P}_{\mathrm{ij}-2}, \mathrm{VP}_{\mathrm{ij}}\end{array}$ & 01111111111 & 0.1656 & 0.0392 & 0.0108 & 0.6624 \\
\hline 3 & $\begin{array}{r}\mathrm{T}_{\mathrm{ij}}, \mathrm{T}_{\mathrm{ij}-1}, \mathrm{~T}_{\mathrm{ij}-2,} \\
\mathrm{RH}_{\mathrm{ij}-1} \mathrm{RH}_{\mathrm{ij}-2} \\
\mathrm{~V}_{\mathrm{ij}}, \mathrm{V}_{\mathrm{ij}-1}, \mathrm{~V}_{\mathrm{i}, \mathrm{j}-1}, \mathrm{P}_{\mathrm{ij}-} \\
{ }_{1}, \mathrm{P}_{\mathrm{ij}-2}, \mathrm{VP}_{\mathrm{ij}}\end{array}$ & 11101111111 & 0.1431 & 0.0758 & 0.0146 & 0.5724 \\
\hline 4 & $\begin{array}{c}T_{\mathrm{ij}}, \mathrm{T}_{\mathrm{ij}-1}, \mathrm{~T}_{\mathrm{ij}-2,2} \mathrm{RH}_{\mathrm{ij}} \\
\mathrm{RH}_{\mathrm{ij}-1} \mathrm{RH}_{\mathrm{ij}-2} \\
\mathrm{~V}_{\mathrm{ij},}, \mathrm{V}_{\mathrm{i}, \mathrm{j}-1}, \mathrm{P}_{\mathrm{ij}-1}, \mathrm{P}_{\mathrm{ij}-\mathrm{-}} \\
{ }_{2}, \mathrm{VP}_{\mathrm{ij}}\end{array}$ & 11111101111 & 0.1504 & 0.0666 & 0.0089 & 0.6016 \\
\hline 5 & $\begin{array}{c}\mathrm{T}_{\mathrm{ij}-1,}, \mathrm{~T}_{\mathrm{ij}-2,2} \mathrm{RH}_{\mathrm{ij}-1} \\
\mathrm{RH}_{\mathrm{ij}-2} \\
\mathrm{~V}_{\mathrm{ij},}, \mathrm{V}_{\mathrm{ij}-1}, \mathrm{~V}_{\mathrm{i}, \mathrm{j}-1}, \mathrm{P}_{\mathrm{ij}-} \\
{ }_{1}, \mathrm{P}_{\mathrm{ij}-2}, \mathrm{VP}_{\mathrm{ij}}\end{array}$ & 01101111111 & 0.1529 & 0.0715 & 0.0152 & 0.6116 \\
\hline 6 & $\begin{array}{c}\mathrm{T}_{\mathrm{ij}-1,}, \mathrm{~T}_{\mathrm{ij}-2,2} \mathrm{RH}_{\mathrm{ij}} \\
\mathrm{RH}_{\mathrm{ij}-1} \mathrm{RH}_{\mathrm{ij}-2} \\
\mathrm{~V}_{\mathrm{ij}}, \mathrm{V}_{\mathrm{i}, \mathrm{j}-1}, \mathrm{P}_{\mathrm{ij}-1}, \mathrm{P}_{\mathrm{ij}-} \\
{ }_{2}, \mathrm{VP}_{\mathrm{ij}}\end{array}$ & 01111101111 & 0.1548 & 0.0756 & 0.0133 & 0.6194 \\
\hline 7 & $\begin{array}{c}\mathrm{T}_{\mathrm{ij}}, \mathrm{T}_{\mathrm{ij}-1}, \mathrm{~T}_{\mathrm{ij}-2,} \\
\mathrm{RH}_{\mathrm{ij}-1} \mathrm{RH}_{\mathrm{ij-}-2,} \\
\mathrm{~V}_{\mathrm{ij-1}-1}, \mathrm{~V}_{\mathrm{i}, \mathrm{j}-1}, \mathrm{P}_{\mathrm{ij}-1}, \mathrm{P}_{\mathrm{ij}-} \\
{ }_{2}, \mathrm{VP}_{\mathrm{ij}}\end{array}$ & 11101101111 & 0.1519 & 0.0647 & 0.0083 & 0.6077 \\
\hline 8 & $\begin{array}{l}\mathrm{T}_{\mathrm{ij}-1}, \mathrm{~T}_{\mathrm{ij}-2,}, \mathrm{RH}_{\mathrm{ij}-1} \\
\mathrm{RH}_{\mathrm{ij}-2}, \mathrm{~V}_{\mathrm{ij}-1}, \mathrm{~V}_{\mathrm{i}, \mathrm{j}} \\
{ }_{1}, \mathrm{P}_{\mathrm{ij}-1}, \mathrm{P}_{\mathrm{ij}-2}, \mathrm{VP}_{\mathrm{ij}}\end{array}$ & 01101101111 & 0.1399 & 0.1260 & 0.0090 & 0.5598 \\
\hline 9 & $\begin{array}{c}\mathrm{T}_{\mathrm{ij}-2,2}, \mathrm{RH}_{\mathrm{ij}-1} \mathrm{RH}_{\mathrm{ij}-2} \\
\mathrm{~V}_{\mathrm{ij}}, \mathrm{V}_{\mathrm{ij}-1}, \mathrm{~V}_{\mathrm{i}, \mathrm{j}-1}, \mathrm{P}_{\mathrm{ij}-} \\
{ }_{1}, \mathrm{P}_{\mathrm{ij}-2}, \mathrm{VP}_{\mathrm{ij}}\end{array}$ & 00101111111 & 0.1597 & 0.0886 & 0.0170 & 0.6390 \\
\hline 10 & $\begin{array}{l}T_{\mathrm{ij}-2,2} \mathrm{RH}_{\mathrm{ij}} \mathrm{RH}_{\mathrm{ij}-1} \\
\mathrm{RH}_{\mathrm{ij}-2, \mathrm{i}} \mathrm{V}_{\mathrm{ij}-1}, \mathrm{~V}_{\mathrm{i}, \mathrm{j}} \\
{ }_{1}, \mathrm{P}_{\mathrm{ij}-1}, \mathrm{P}_{\mathrm{ij}-2}, 2, \mathrm{VP}_{\mathrm{ij}}\end{array}$ & 00111101111 & 0.1784 & 0.0273 & 0.0118 & 0.7139 \\
\hline
\end{tabular}


Table.3 Comparison of various ANN models to select the best model during training

\begin{tabular}{|c|c|c|c|c|}
\hline Model No. & Network & $\begin{array}{c}\text { RMSE } \\
\text { (mm) }\end{array}$ & $\mathbf{r}$ & CE \\
\hline 1 & $9-1-1$ & 13.33 & 0.65 & 0.42 \\
\hline 2 & $9-4-1$ & 12.51 & 0.70 & 0.49 \\
\hline 3 & $9-5-1$ & 11.73 & 0.75 & 0.55 \\
\hline 4 & $9-7-1$ & 11.27 & 0.77 & 0.59 \\
\hline 5 & $9-8-1$ & 10.51 & 0.80 & 0.64 \\
\hline 6 & $9-10-1$ & 9.80 & 0.83 & 0.68 \\
\hline 7 & $9-12-1$ & 9.10 & 0.85 & 0.73 \\
\hline 8 & $9-13-1$ & 13.10 & 0.68 & 0.45 \\
\hline 9 & 9-14-1 & 10.30 & 0.81 & 0.70 \\
\hline 10 & $9-11-1$ & 8.24 & 0.88 & 0.77 \\
\hline 11 & $9-4-4-1$ & 9.27 & 0.84 & 0.72 \\
\hline 12 & $9-5-5-1$ & 8.94 & 0.83 & 0.74 \\
\hline 13 & $9-7-7-1$ & 8.59 & 0.85 & 0.76 \\
\hline 14 & 9-8-8-1 & 7.26 & 0.91 & 0.86 \\
\hline 15 & $9-10-10-1$ & 7.84 & 0.89 & 0.80 \\
\hline 16 & $9-12-12-1$ & 8.03 & 0.88 & 0.79 \\
\hline 17 & $9-14-14-1$ & 9.76 & 0.79 & 0.69 \\
\hline 18 & $9-13-13-1$ & 8.40 & 0.86 & 0.77 \\
\hline
\end{tabular}


Fig.1 Location map of study area

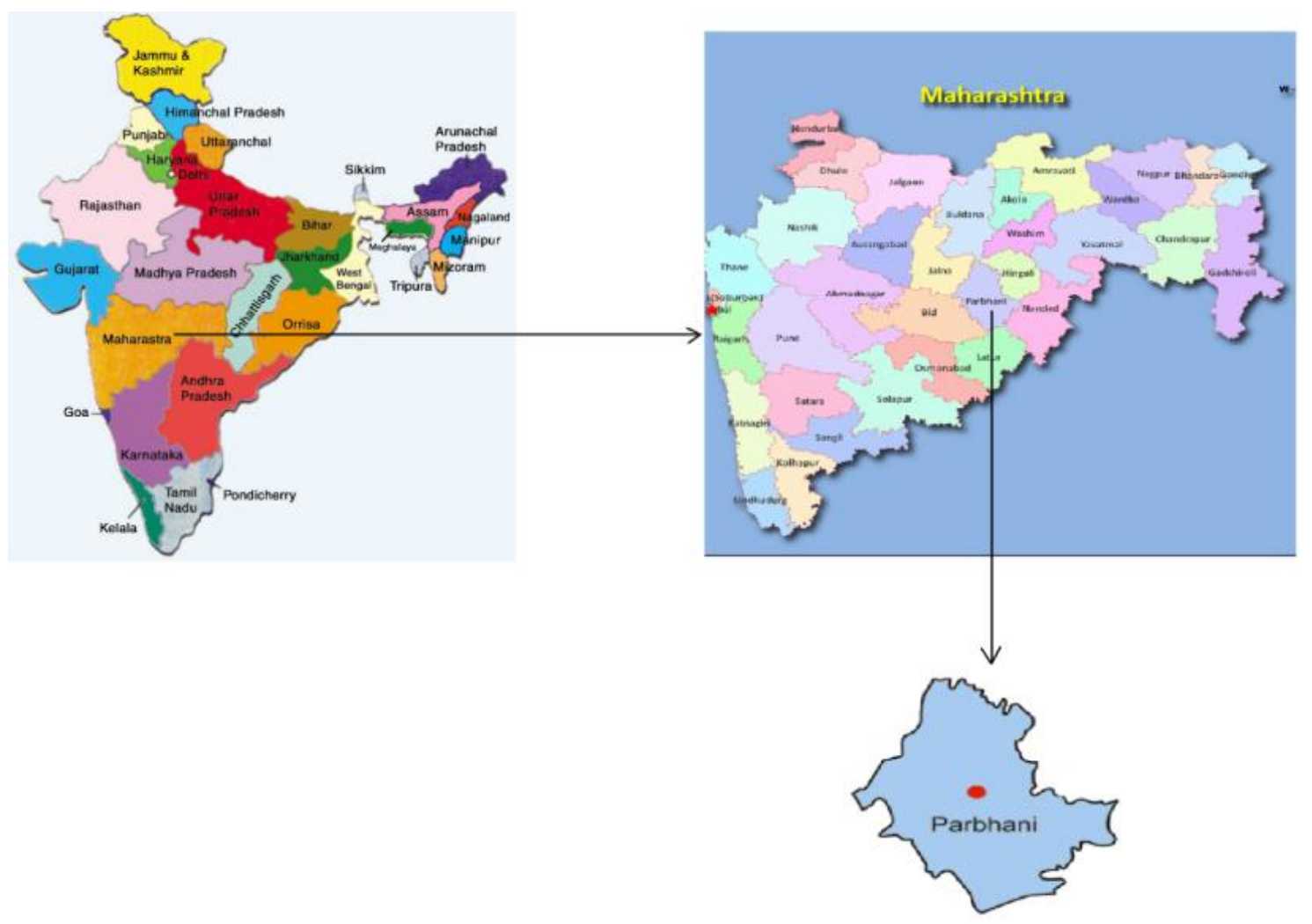

Fig.2 Basic structure of neural network

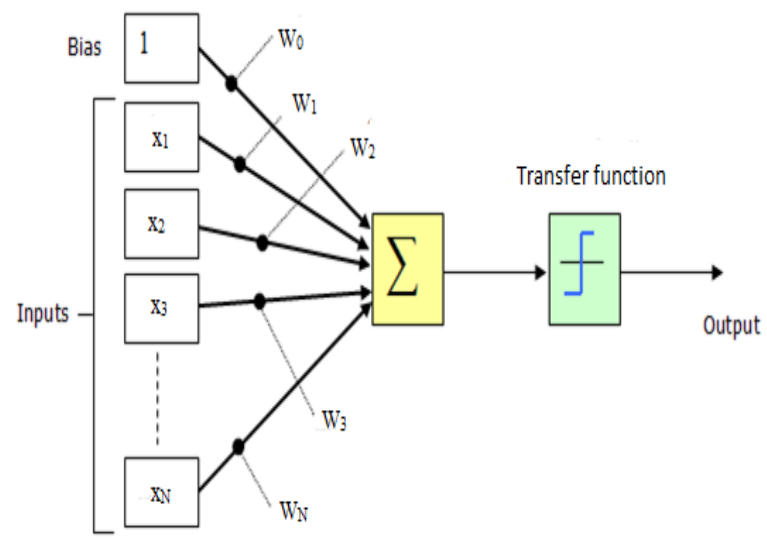


Fig.3 Comparison of observed and predicted rainfall and their corresponding scatter plot for ANN (9-11-1) model during training period

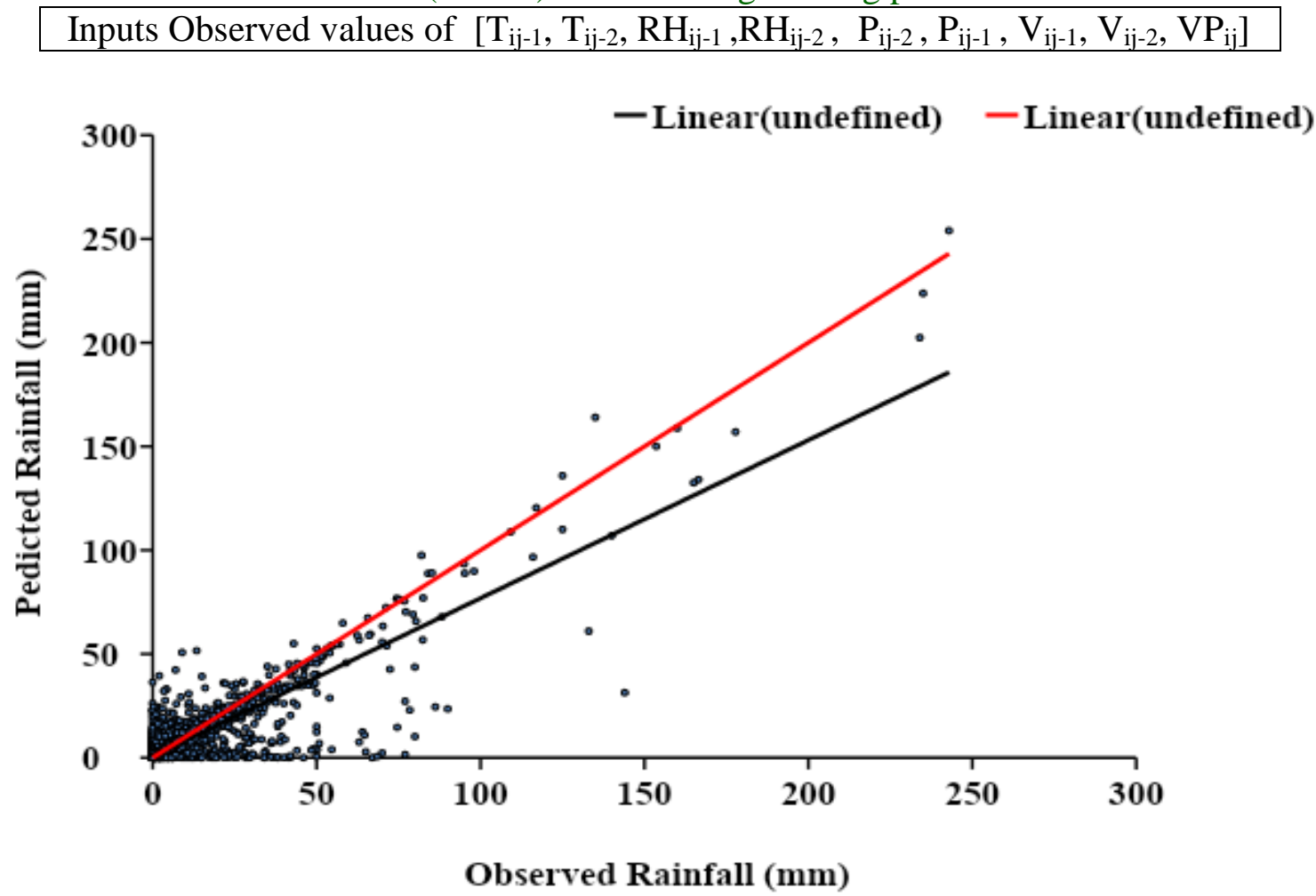

Fig.4 Comparison of observed and predicted rainfall and their corresponding scatter plot for ANN (9-8-8-1) model during training period

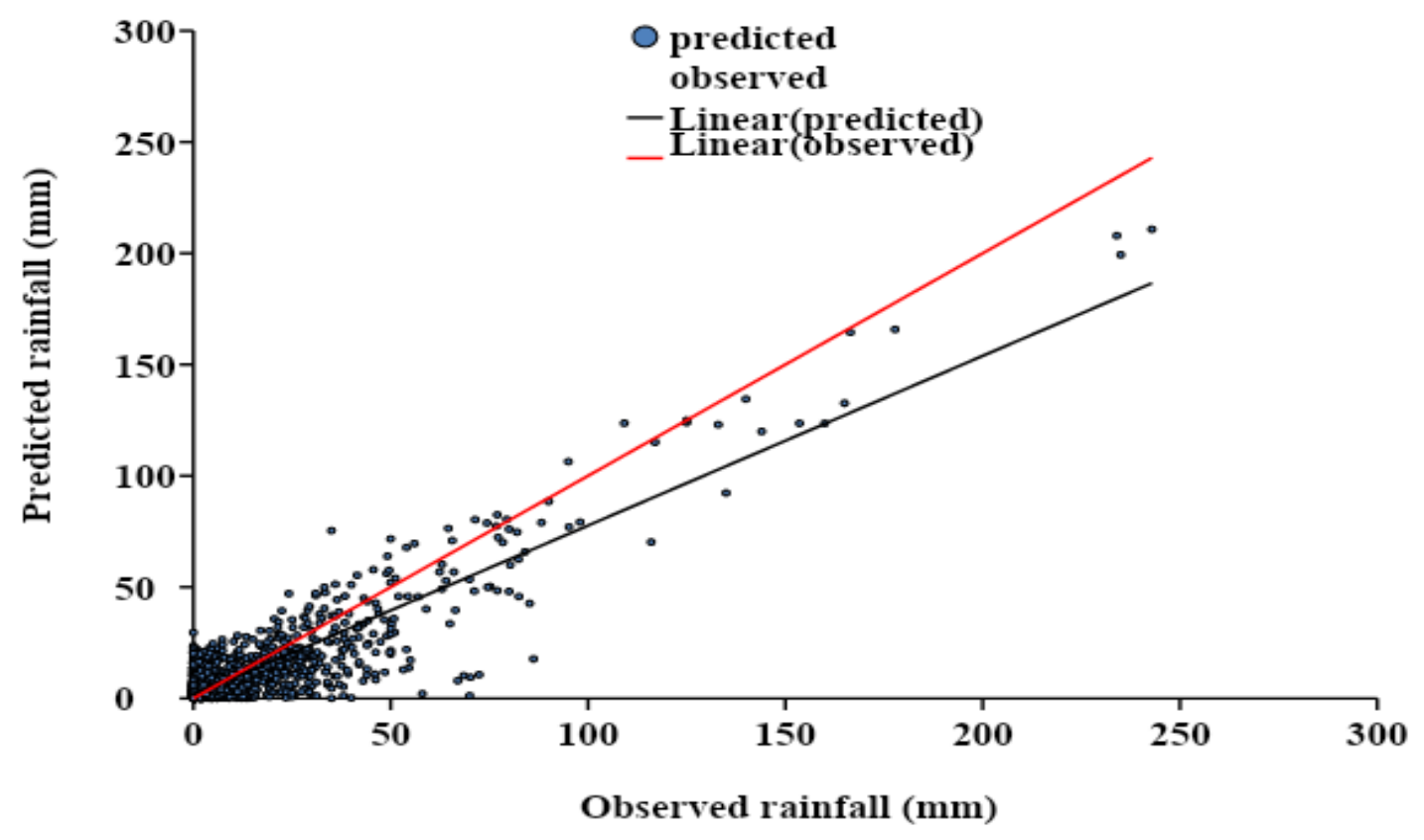


Fig.5 Comparison of observed and predicted rainfall and their corresponding scatter plot for ANN (9-11-1) model during testing period

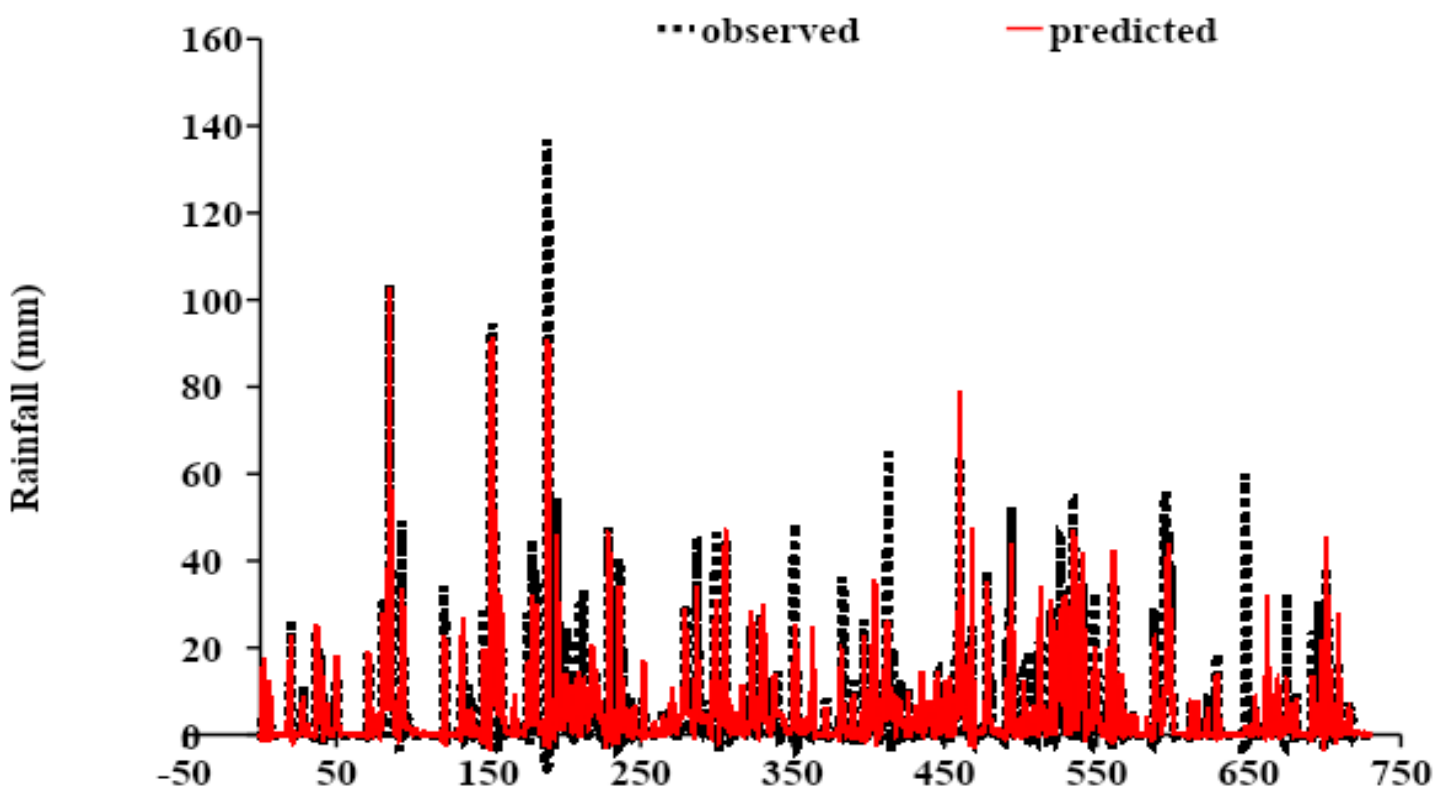

Days

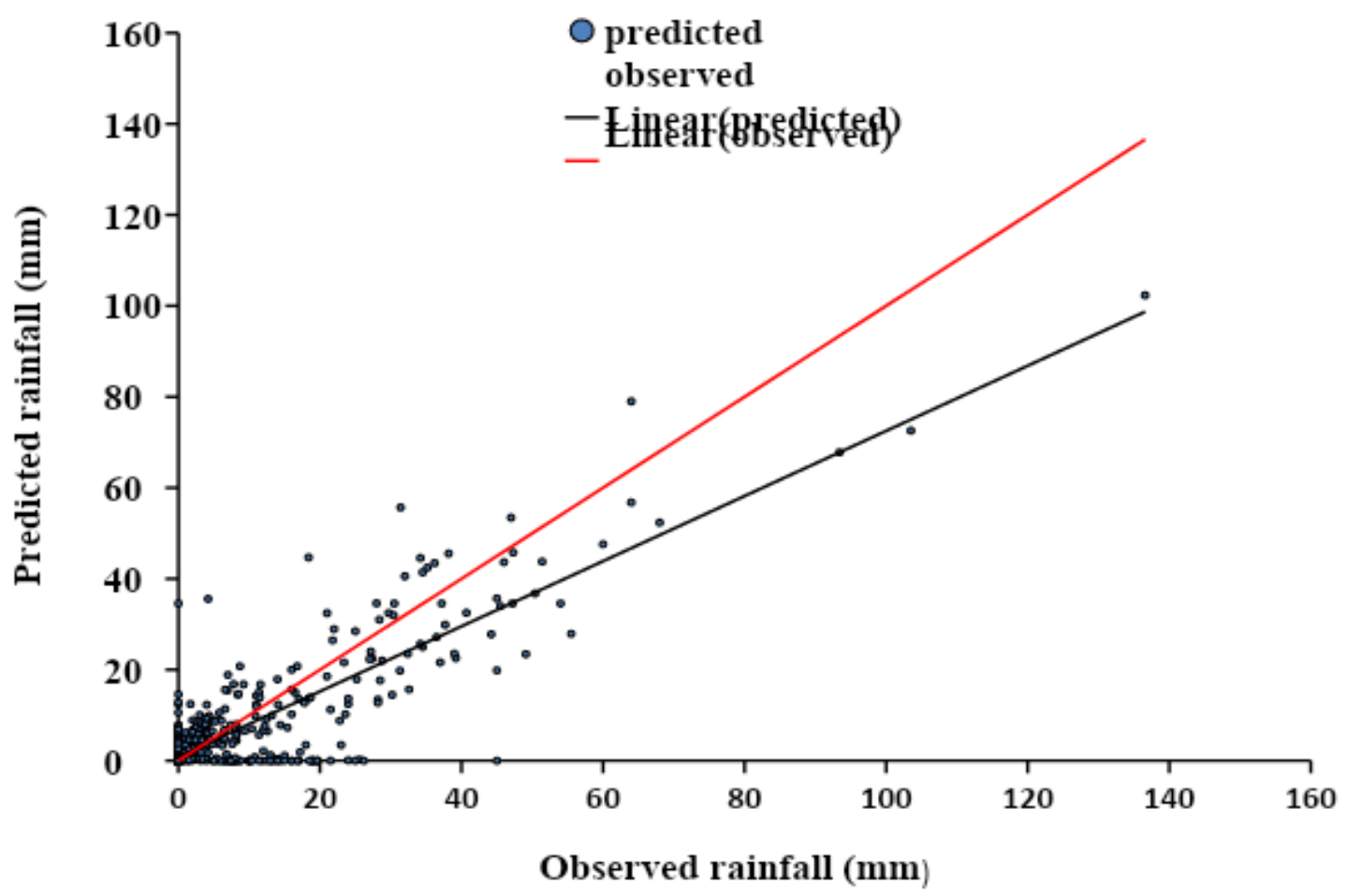


Fig.6 Comparison of observed and predicted rainfall and their corresponding scatter plot for ANN (9-8-8-1) model during testing period
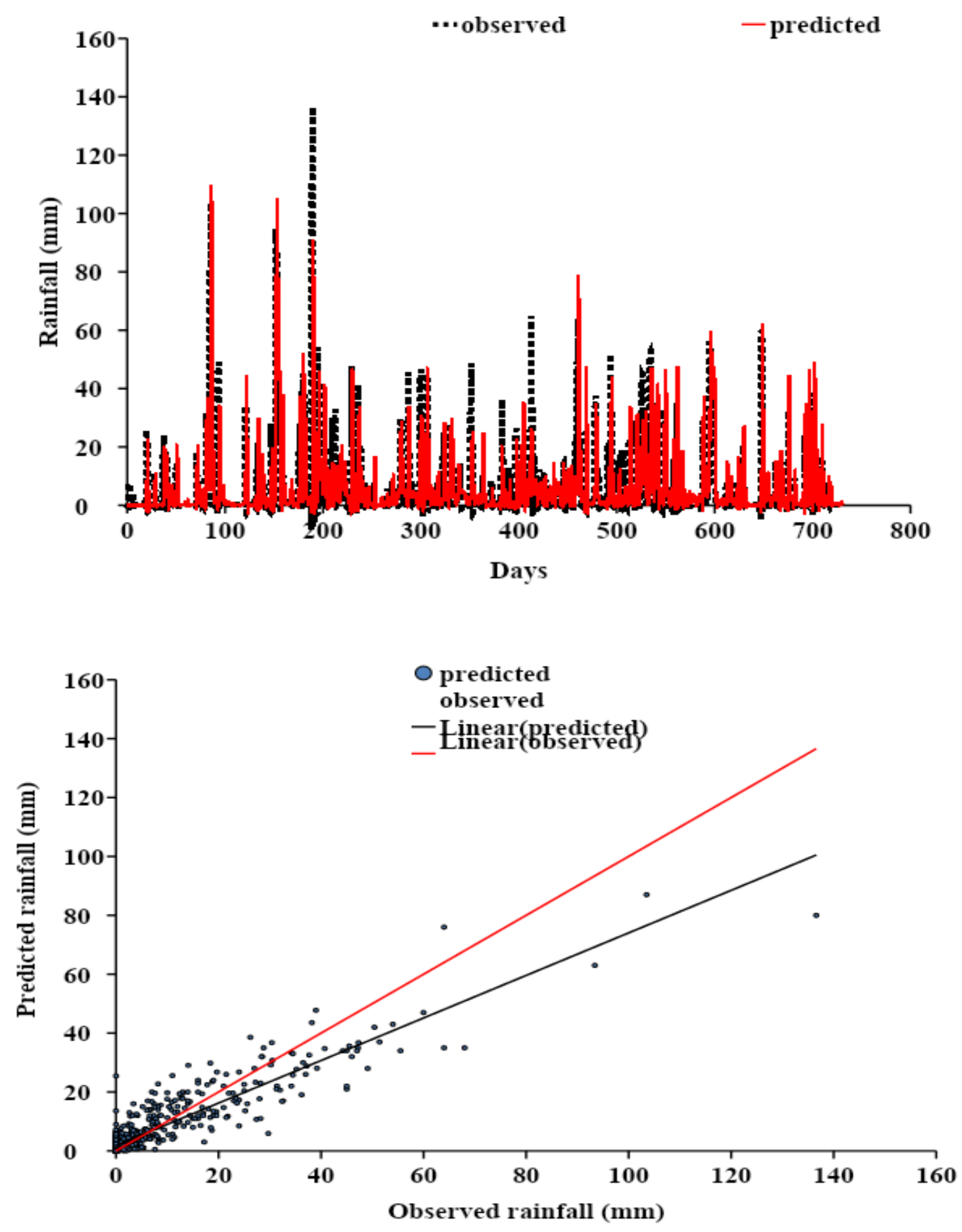
In the model (9-11-1), 9 shows input nodes in the input layer, 11 indicates the 11 number. of neurons in the hidden layer and 1 show the output node in the output layer and in model (9-8-8-1), 9 shows input nodes in the input layer, 8 indicates 8 number of neurons in first hidden layer and second hidden layer, respectively and 1 shows the output node in output layer.

\section{Performance evaluation of developed models}

The qualitative evaluation of the model is based on the visual comparison i.e. overall shape of the observed and predicted plotted graphs. The observed and predicted values of rainfall during training years (1985-2008) using ANN models with two selected networks are presented in Figs. 4 and 5. The observed and predicted values of rainfall for testing years (2009-2014) of ANNs are shown in Figs. 6 and 7.

It is observed that there is a close or nearly close agreement between the predicted and observed rainfall, and overall shape of the plot of predicted rainfall is similar to that of the observed rainfall. It is observed that the regression line is exactly below the best fit line (1:1 line), which indicates that all the models under predict the rainfall values for the Parbhani Maharashtra. It is clear from these figures that the developed models give satisfactory results for rainfall prediction and it may be regarded as fairly satisfactory on the basis of qualitative evaluation during testing period. Therefore, qualitative performance during training and testing has been found satisfactory.

The rainfall forecasting is very essential for planning and management of water resources. Rainfall is one of the most complex and difficult elements of the hydrologic cycle to understand and to model due to the complexity of the atmospheric processes. In this study ANN has been used to rainfall forecasting. ANNs can identify and learn correlated patterns between input data sets and corresponding target values. In the methodologies available to predict the rainfall, the two factors which need to be estimated with utmost accuracy are the quantum of rainfall and time. The performance of developed models was evaluated using qualitatively. Different structures of ANN model were trained and tested for maximum iterations of 1000 for single and double hidden layers network for forecasting the rainfall. Trial and error method was used for the selection of the network among various structures of the ANN model because there is no specific rule available to determine the best structure of the network.

The following conclusions are drawn from the results of this study:

The qualitative performances, based on observed and predicted values during training as well as testing periods of developed models regarded as satisfactory.

Based on the statistical and hydrological indices, performance of ANN model (9-8-8-1) is better than the model (9-11-1) for forecasting monsoon rainfall.

It is concluded that after resolving the rainfall data using wavelet transform with three and four level of resolution and then put into the neural network exhibits better result than without resolved data.

\section{References}

Agrawal, P.K., Somvanshi, V.K., Pandey, O.P., Kalanker, N.V., Prakash, M.R. and Chand, R. 2006. Modeling and prediction of rainfall using artificial neural network and ARIMA 
techniques. Journal of Indian Geophysics Union, 10(2): 141-151.

ASCE 2000a. Task committee on application of neural networks in hydrology. Artificial neural networks in hydrology I: Preliminary concepts. Journal of Hydrologic Engineering, 5(2): 115123.

ASCE 2000b. Task committee on application of neural networks in hydrology. Artificial neural networks in hydrology II: Hydrology application. Journal of Hydrologic Engineering, 5(2): 124137.

El-shafie, M. Mukhlisin, A. Najah Ali and M.R., Taha, 2011a. Performance of artificial neural network and regression techniques for rainfall-runoff prediction, International Journal of the Physical Sciences, 6(8): 1997-2003.

French, M.N., Krajewski, W. F. and Cuykendall, R. R. 1992. Rainfall forecasting in space and time using a neural network. Journal of Hydrology, 137(1-4): 1-31.

Gadgay, B., Kulkarni, S. and Chandrashekhar, B. 2011. A Neural Network model to predict rainfall in large Indian cities. World Journal of Science and Technology. 1(8): 2231-2587.

Hung, N.Q., Babel, M.S., Weesakul, S. and Tripathi, N.K. 2009. An artificial neural network model for rainfall forecasting in Bangkok, Thailand. Hydrology and Earth System Sciences, 13(8), 1413-1425.

Jain, S.K., Das, A. and Srivastava, D.K. 1999. Application of ANN for reservoir inflow prediction and operation. Journal of water resources planning and management, 125(5): 263-271.

Jyothi Prakash, V., Ramchandran, M.R. and Shanmuganathan, P., 2002. Artificial neural network model for estimation of Reference Evapotranspiration. The
Institution of Engineers (India), 83: 17-24.

Kumar, A.M. and Jain, A. 2007. Hybrid neural network models for hydrologic time series forecasting. Applied Soft Computing, 7(2), 585-592.

Lin, G. F. and Chen, L. H. 2005. Application of an artificial neural network to typhoon rainfall forecasting. Hydrological Processes: An International Journal, 19(9): 18251837.

Luk, K.C., Ball, J.E. and Sharma, A. 2001. An application of artificial neural networks for rainfall forecasting. Mathematical and Computer Modelling 33: 883-699.

Mishra N, Soni H.K., Sharma, S., and Upadhyay, A.K. 2018. Development and analysis of artificial neural network models for rainfall prediction by using time-series data. International Journal of Intelligent Systems and Applications, 10(1): 16-19.

Nastos, P.T., Moustris, K.P., Larissi, I.K. and Paliatsos, A.G. 2013. Rain intensity forecast using Artificial Neural Networks in Athens, Greece. Atmospheric Research, 199: 153-160.

Pai, M.L., Pramod, K.V. and Balchand, A.N. 2014. Long range forecast on south west monsoon rainfall using artificial neural networks based on clustering approach. International Journal of Information Technology and Computer Science, 6(7): 1-8.

Partal, T. and Cigizoglu, H.K., 2009. Prediction of daily precipitation using wavelet-neural networks. Journal of Hydrological Sciences, 54(2): 234246.

Pulido-Calvo, I. and Portela, M.M. 2007. Application of neural approaches to one-step daily flow forecasting in Portuguese watersheds. Journal of Hydrology, 332(1-2): 1-15. 
Rajurkar, M. P., U.C. Kothyari. and U.C. Chaube. 2004. "Modeling of the daily rainfall-runoff relationship with artificial neural network." Journal of Hydrology 285, no. 1-4 (2004): 96113.

Ramirez, M. C. V., de Campos Velho, H. F. and Ferreira, N. J. 2005. Artificial neural network technique for rainfall forecasting applied to the Sao Paulo region. Journal of Hydrology, 301(14): 146-162.

Singh, C.V. 2006. Pattern characteristics of Indian monsoon rainfall using principal component analysis (PCA). Atmospheric research, 79(3-4): 317326.
Tokar, A.S. and Markus, M. 2000. Precipitation-runoff modeling using artificial neural networks and conceptual models. Journal of Hydrologic Engineering, 5(2): 156-161

Wu, C. L. and Chau, K.W. 2006. A flood forecasting neural network model with genetic algorithm. International journal of environment and pollution, 28(3-4): 261-273.

Xie, P., Chen, M., Yang, S., Yatagai, A., Hayasaka, T., Fukushima, Y., and Liu, C. 2006. A gauge-based analysis of daily precipitation over East Asia. Journal of Hydrometeorology, 8(3): 607-626.

\section{How to cite this article:}

Amit Rawat, Pravendra Kumar and Vaibhav Deoli. 2019. Daily Monsoon Rainfall Prediction using Artificial Neural Network (ANN) for Parbhani District of Maharashtra, India. Int.J.Curr.Microbiol.App.Sci. 8(12): 1949-1963. doi: https://doi.org/10.20546/ijcmas.2019.812.233 